\title{
Corrigendum: Tumor necrosis factor alpha maintains denervation-induced homeostatic synaptic plasticity of mouse dentate granule cells
}

\author{
Denise Becker, Nadine Zahn, Thomas Deller and Andreas Vlachos* \\ Institute of Clinical Neuroanatomy, Neuroscience Center, Goethe-University Frankfurt, Frankfurt, Germany \\ *Correspondence: a.vlachos@med.uni-frankfurt.de \\ Edited and reviewed by: \\ Tycho M. Hoogland, Netherlands Institute for Neuroscience, Netherlands
}

Keywords: entorhinal cortex lesion, homeostatic synaptic scaling, astrocytes, brain injury, organotypic slice culture

\section{A commentary on}

Tumor necrosis factor alpha maintains denervation-induced homeostatic synaptic plasticity of mouse dentate granule cells

by Becker, D., Zahn, N., Deller, T., and Vlachos, A. (2013). Front Cell Neurosci. 7:257. doi: 10.3389/fncel.2013.00257

We noticed that in Figure $2 \mathrm{C}$ of our article the sample traces shown for nondenervated controls and for denervated TNF $\alpha$-deficient preparations at 3-4 days post lesion $(\mathrm{dpl})$ are identical. Upon re-examination of the original recordings, we found that this sample trace was taken from a denervated dentate granule cell ("3-4 dpl group"). The corrected figure showing a sample trace of a non-denervated control is now presented. We apologize for the mistake and for any inconvenience caused to the readers.

Conflict of Interest Statement: The authors declare that the research was conducted in the absence of any commercial or financial relationships that could be construed as a potential conflict of interest.
Received: 02 July 2014; accepted: 23 July 2014; published online: 12 August 2014.

Citation: Becker D, Zahn N, Deller T and Vlachos A (2014) Corrigendum: Tumor necrosis factor alpha maintains denervation-induced homeostatic synaptic plasticity of mouse dentate granule cells. Front. Cell. Neurosci. 8:230. doi: 10.3389/fncel.2014.00230

This article was submitted to the journal Frontiers in Cellular Neuroscience.

Copyright (c) 2014 Becker, Zahn, Deller and Vlachos. This is an open-access article distributed under the terms of the Creative Commons Attribution License (CC BY). The use, distribution or reproduction in other forums is permitted, provided the original author(s) or licensor are credited and that the original publication in this journal is cited, in accordance with accepted academic practice. No use, distribution or reproduction is permitted which does not comply with these terms. 


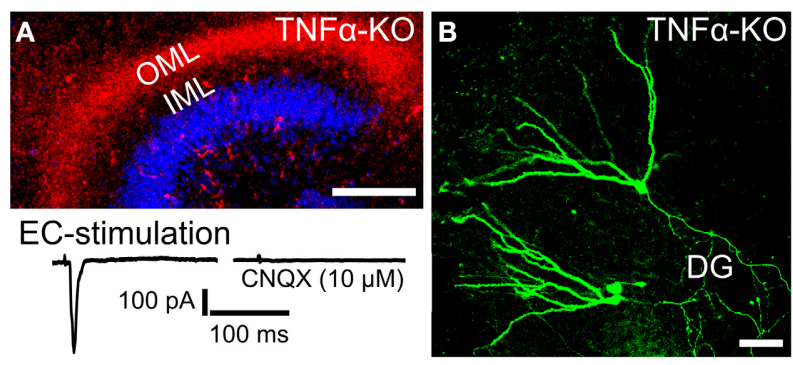

C

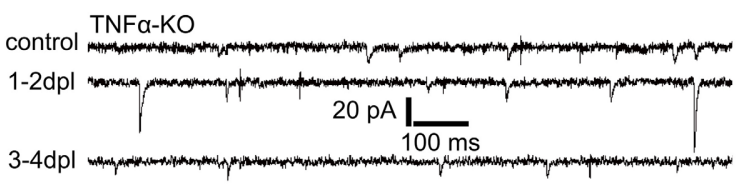

D

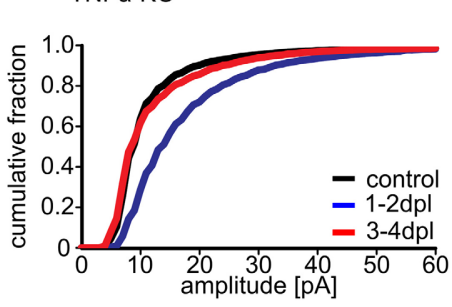

E TNFa-KO

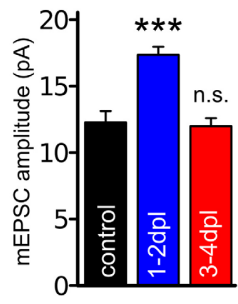

FIGURE 1 | Figure legend same as in the original article: Denervation-induced homeostatic synaptic strengthening is not observed in granule cells of TNF $\alpha$-deficient slice cultures at 3-4 dpl. (A) Mini-Ruby tracing of entorhino-hippocampal axons (red; ToPRO nuclear staining, blue) and electrical stimulations of the entorhinal cortex (EC) while recording evoked EPSCs from dentate granule cells revealed an intact and functional entorhino-hippocampal projection in slice cultures prepared from $\mathrm{TNF} \alpha$-deficient mice (TNF $\alpha-\mathrm{KO}$; three independent experiments each, up to 50 traces averaged per neuron). Evoked EPSCs (amplitude: $369 \pm 102$ pA) could be blocked by the AMPA-receptor antagonist CNQX (10 $\mu \mathrm{M}$; amplitude: $9.6 \pm 2.1 \mathrm{pA})$. Scale bar: $200 \mu \mathrm{m}$. (B) Patched granule cells were filled with biocytin and post hoc identified using Alexa568- or Alexa488-streptavidin. Scale bar: $50 \mu \mathrm{m}$. (C-E) Whole-cell patch-clamp recordings from granule cells of TNF $\alpha$-deficient slice cultures revealed an increase in the mEPSC amplitudes at 1-2 dpl but not at 3-4 dpl ( $n=12-16$ neurons per group, from six to eight cultures each). Data represent mean \pm s.e.m.; ${ }^{* * *} p<0.001$; n.s., not significant. 